\section{Grasp Reflex}

Stephen P. Salloway

Butler Hospital Alpert Medical School of Brown University, Providence, RI, USA

\section{Synonyms}

Palmar grasp reflex

\section{Definition}

The grasp reflex is elicited by stroking the palmar surface of the patient's hand, causing the fingers to close and grasp any object left in the hand. It is one of the frontal release signs, primitive reflexes that are normal in infants, disappear with brain maturation allowing inhibition, and reappear (are "released") in disorders that affect the frontal lobes. Like most primitive reflexes, the grasp reflex has evolutionary/adaptive advantage in infant apes, allowing to cling automatically to their mother's hair. This reflex appears at birth and persists until 5 or 6 months of age, after which it is thought to indicate damage to the contralateral frontal lobe.

\section{References and Readings}

Goetz, C. G. (2007). Textbook of clinical neurology (3rd ed.). Philadelphia: Saunders. 